Earth \& Environment | Yukitake Shioi

\title{
Predicting post-seismic liquefaction through geological response analysis
}

During liquefaction, solid sandy ground behaves like a liquid posing a significant threat earthquake-prone regions. saturated sandy sediments saturated sandy sediments To address and flooding understanding, Prof Yukitake Shioi from the Hachinohe Institute of Technology in Japan applied a finite element method model to observations from the 1994 Far-Off Sanriku Earthquake. Results show that waves from bedrock become wrapped in undergoing multiple reflections and moving repeatedly backwards and forwards. The extent of liquefaction depends on earthquake magnitude, thickness and physical properties of sedimentary layers, as well as the scale of prototype seismic

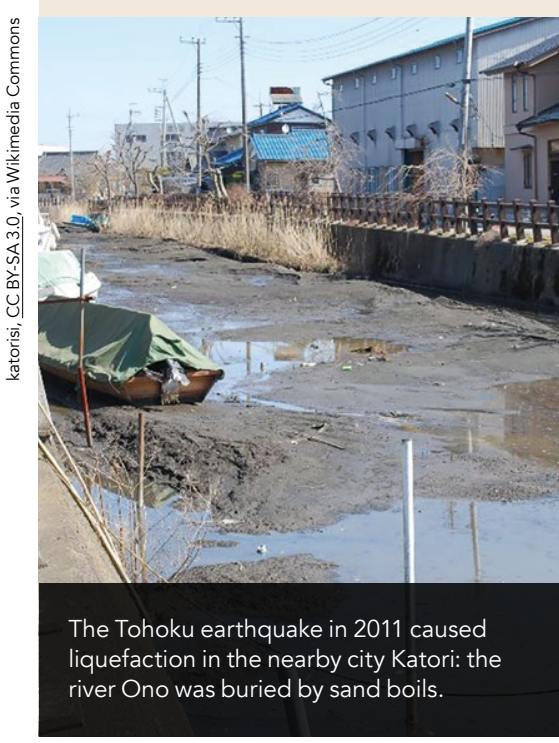

n simple terms, liquefaction is a process by which solid saturated sandy ground behaves as a liquid. While widely recognised in the scientific community, this phenomenon is less known among the public at large, earthquake-prone regions.

During earthquakes, large shear strain waves and the associng seartions can and sediment particles to lose contact with each other. As a result, the materia becomes unable to support weight

tarts to behave as a fluid. This primarily impacts ground that has excess pore water pressure (meaning the ground is water-saturated) and is formed by loose sediments. While the condition is usually temporary, quefs, ground sus in the exuption of sand boll, ground subsictice and looding, and severe earthquake-related damage around the world In all but the very largest earthouakes, liquefaction is limited to the upper sedimentany layers. The widely accepted theory of liquefaction suggests that its occurrence depends

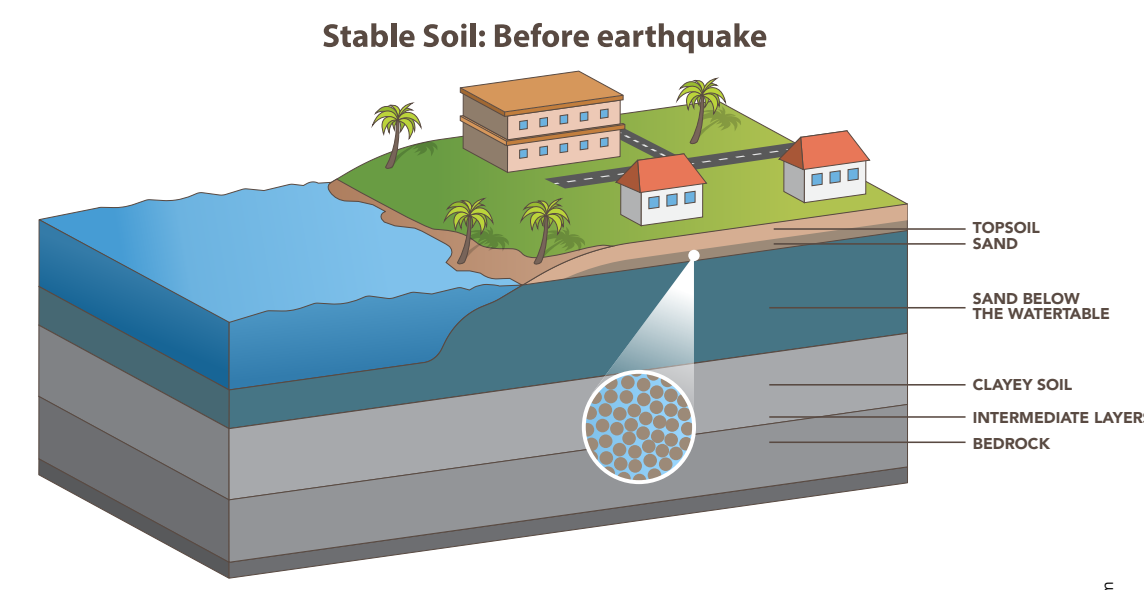

Liquified Soil: During and after the earthquake

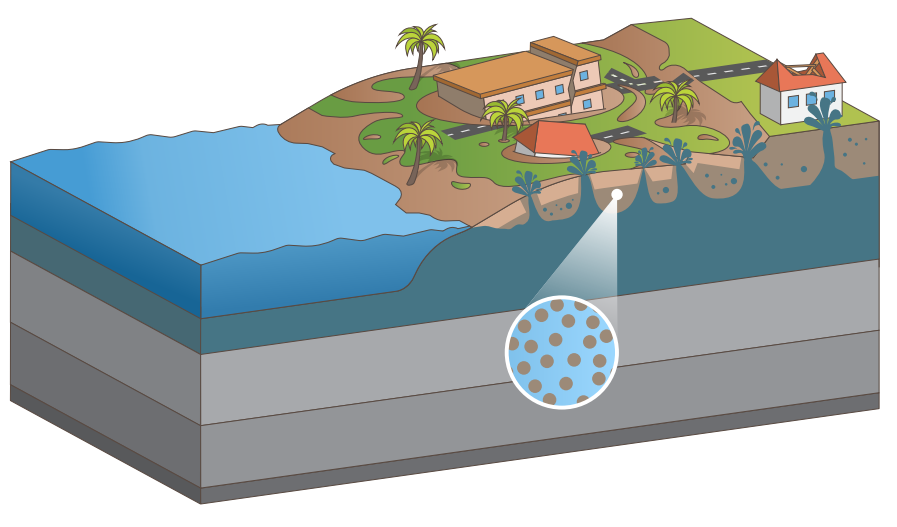

Fig 1 During earthquakes, large shear strain waves and the associated vibrations can
surface saturated sandy soil and sediment particles to lose contact with each other. on strong ground acceleration (during (t) However, this theory cannot explain four key phenomen: (1) the maximum accelerations observed at liquefaction sites are not large - in particular liquefaction occurs after the main shock during which long period waves with low acceleration are dominant; (2) liquefaction can sometimes continue for a long time after an earthquake; (3) sometimes, quefaction is also seen in gravel or sit layers; and (4) sometimes, large land movements by liquefaction occur without sand boils and water springs, despite all

TOWARDS A NEW

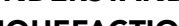

LOUEACION

To address these gaps in our Yuktake Shio of the Hachin, Prof

Institute of Technology in Japan, and

his collaborators DrYutaka Hashizume and Dr Hisashi Fukada, have developed a new hypothesis of liquefaction based on observations from earthquakes in Japan, including the 1994 Far-Off Sanriku Earthquake. This event had a magnitude of 7.5 and caused significant liquefactionrelated damage in the Hachinohe Port area, some $200 \mathrm{~km}$ west of the epicentre. However, the style of liquefaction varied between an older area of the port, where land had been reclaimed in the 1950s, and a newer area, on land developed in the 1970s. In the former, only minor sater extensive sand bo scales, along with ground subsidence and displacement of quays occurred.

Prof Shioi's team theorised that seismic waves from the bedrock are reflected at boundaries with other layers. In their
multi-reflection theory, large shear strain waves become 'trapped' in soft near-surface sedimentary layers. Through a rising process they reflections and refraction rections and refractions, moving There

Waves become "trapped" in soft near-surface sedimentary layers. Through $h \begin{gathered}\text { waves reached the } \\ \text { surface through }\end{gathered}$ a rising process they undergo multiple soft layers, their repeatedly backwards and forwards. continued long after the main
(4) despite the low 
and large energy were sufficient to liquefy the upper saturated sand layer; and (5) bedrock to the surface. In addition, they also found that liquefaction required that waves be initiated in the bedrock, and that relatively large seismic energy was needed to initiate liquefaction.

To confirm the accuracy of their model, Prof Shioi's team applied the FLUSH model to scenarios based on other large earthquakes. They found that they could reproduce observed liquefaction following the 1964 M7.5 Niigata Earthquake, the 1983 M7.7 Mid

\section{ENGINEERING A SOLUTION} With their research, Prof Shioi's team has liquefaction at a given site requires an understanding of the dynamic responses of both the bedrock and overlying layers during an earthquake. Predicting the liquefaction risk requires response analysis that is specific to the local geology (that is the bedrock and overlaying sedimentary layers) and potential earthquake magnitude. The responses of the various layers of material and rocks depend on their physical properties, which can be investigated using geophysical techniques. Allowing hazard managers

Prof Shioi's team has shown that predicting the possibility of liquefaction at a given site requires an understanding of the dynamic responses of both the bedrock and overlying

layers during an earthquake.

Japan Sea Earthquake (which caused liquefaction in Noshiro city and Kizukur town, both $100 \mathrm{~km}$ from the epicenter but with different underlying geological structures), and the 1948 M7.1 Fukui Earthquake. In each case, the results showed that seismic waves become amplified from depth to the surface. Eollowing the 2011 M9.0 East Japan Earthquake, the researchers confirmed drilling shows a partially liqueried rend hyer above a ber of clay (see figure 3).

to better predict the lateral extent and improved hazard mitigation strategies. In general, approaches to minimising damage caused by liquefaction require engineering solutions.

In urban areas, avoiding the development of buildings and infrastructure on land at As As such, engineening approaches have involved. For example, groundwater in

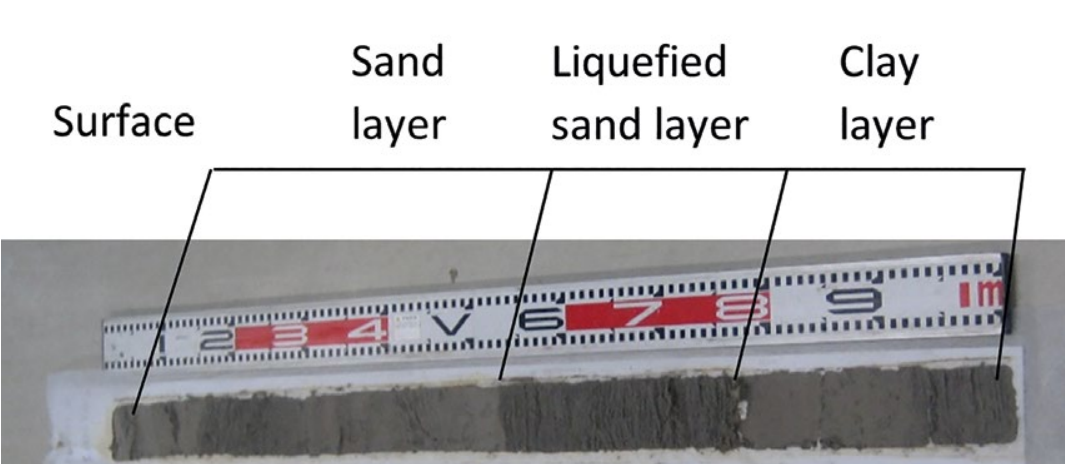
Fig 3 Aftermath of the 2011 Tohoku earthquake: drilling of the near-surface layer of soil shows a
partially liquefied sand layer above a layer of clay.
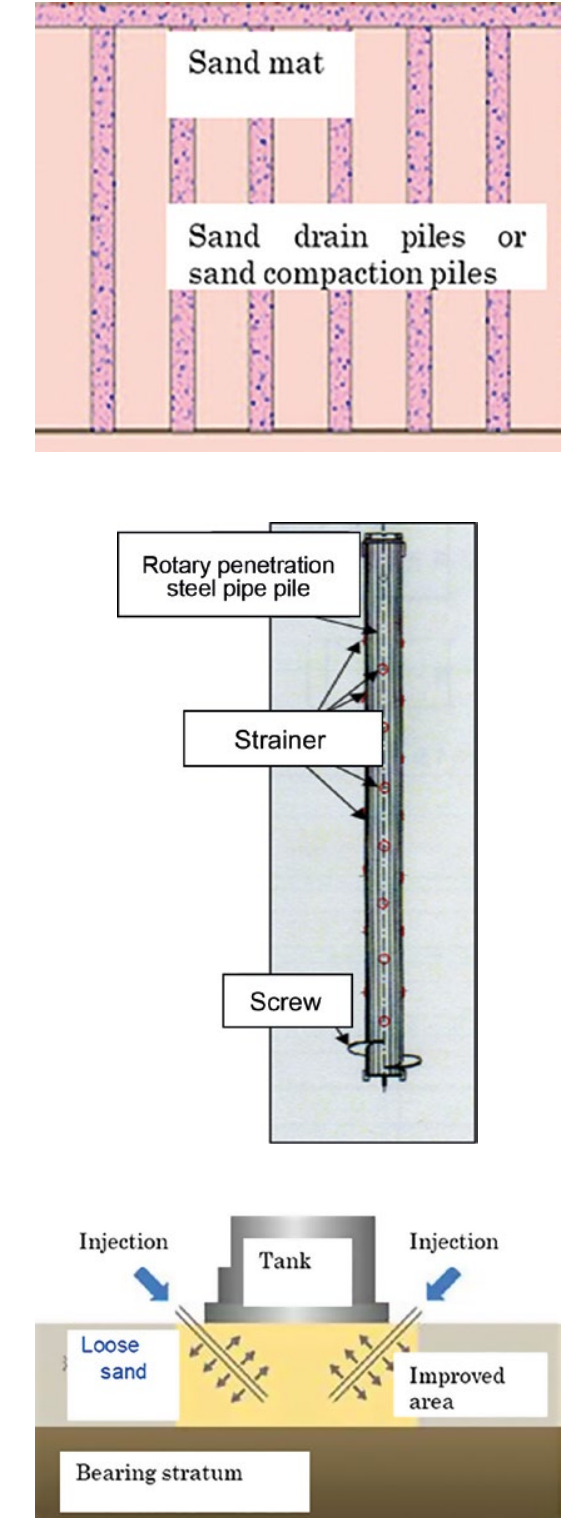

Fig 4 Examples for countermeasures against

the saturated sandy layer on the surface can be removed by piling (driving (a) gravel drain piling. Shear deformation of saturated sandy layers can be reduced by building rigid diaphragm walls (that is, underground walls). Finally, the ground can be strengthened by the injection of cement and/or other chemicals, or by the installation of reliable foundations. In a similar vein, existing houses and buildings can be protected by installing small diameter steel pipes with slits or small holes at intervals of a few meters around them using piling equipment, by installing rigid diaphragm walls around buildings reducing the groundwater level.

E: yshioi@blue.plala.or.jp T: +81 178257724

\section{Research Objectives}

Prof Shioi studies the mechanics of liquefaction following an earthquake.

\section{Detail}

Yukitake Shioi is Professor Emeritus at Hachinohe Institute of Technology in Japan and Honorary Member of the Japanese Geotechnical Society and the Japan Society of Civil Engineering. His research interests include bridge engineering, foundation engineering, structura ngineering and highway engineering

\section{Collaborators}

Dr Hisashi Fukada

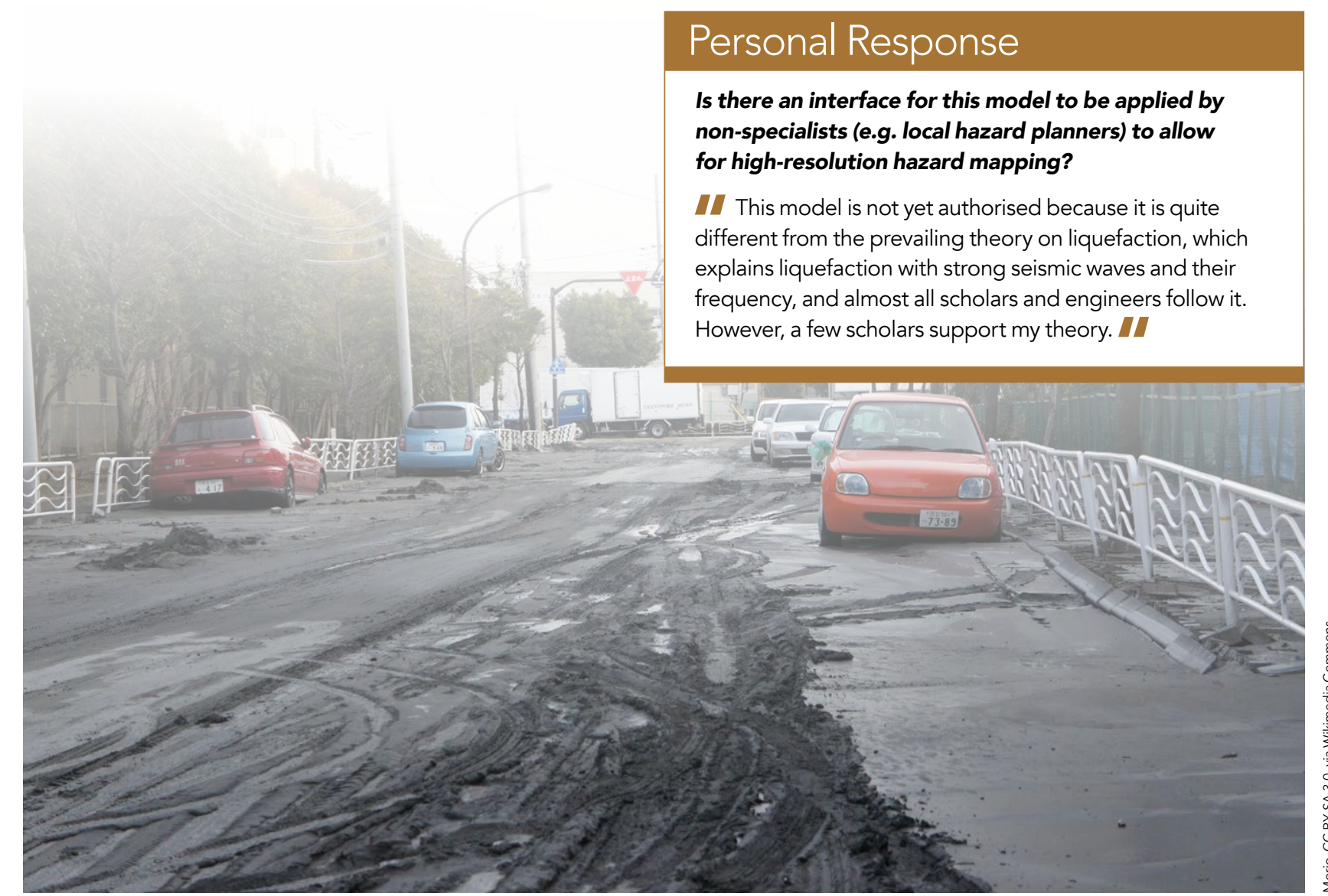

References

Shioi, Y. and Hashizume, Y. (2020). Ground damage during Long, P. and Dung, N. (eds). Geotechnics for Sustainable Infrastructure Development. Lecture Notes in Civil Engineering, 62. Springer, Singapore. Available at
https://doi.org/10.1007/978-981-15-2184-3 117

Shioi, Y. and Hashizume,Y. (2016). Mechanism, quantative calculation and countermeasures of liquefaction during Engineering, Lisbon, Portugal.

Shioi, Y., Fukada, H., Hashizmue, Y. (2006). Liquefaction Mechanism of Sandy Ground and Influence of Suffece Layer Hardness. $8^{\text {th }}$ National Conference on Earthquale Engineering, US. tion hazard mapping? However, a few scholars support my theory - 